\title{
A review on differential scanning calorimetry as a tool for thermal assessment of nanostructured coatings
}

\author{
Anca Elena Slobozeanu ${ }^{1}$, Simona Elena Bejan ${ }^{1, *}$, Ioan Albert Tudor ${ }^{1}$, Ana-Maria Mocioiu ${ }^{1}$, Adrian Mihail Motoc ${ }^{1, *}$ \\ Maria Dolores Romero-Sanchez ${ }^{2}$, Mihai Botan ${ }^{3}$, Cristea George Catalin ${ }^{3}$, Cursaru Laura Madalina ${ }^{1}$, \\ Radu Robert Piticescu ${ }^{1}$, and Cristian Predescu ${ }^{4}$ \\ ${ }^{1}$ National R\&D Institute for Nonferrous and Rare Metals-IMNR, 102 Biruintei Blvd. Pantelimon, Ilfov, Romania \\ 2 Applynano Solutions, S.L., Scientific Parc of Alicante. Carretera San Vicente, s/n. Alicante, Spain \\ ${ }^{3}$ National R\&D Institute for Aerospace Research Elie Carafoli, 102 Iuliu Maniu Blvd. Bucharest 6, Romania \\ ${ }^{4}$ Material Sciences and Engineering, University Politehnica of Bucharest, 313 Splaiul Independentei, Bucharest, Romania
}

Received: 26 August 2020 / Accepted: 16 December 2020

\begin{abstract}
Nanostructured coatings and films play an important role in modern surface engineering due to their ability to improve and optimize materials behavior under different external constraints such as high/low temperatures, stress/strain, corrosive/oxidizing atmosphere, electromagnetic fields/fluxes etc., used practically in all industrial fields. Surface modification may be done using any type of materials: polymers, metals, ceramics, composites or hybrids on any type of substrate by different physical, chemical or combined technologies. Thermal characterization methods are one of the most accessible tools to study, model and predict the process parameters required to preserve the nanostructures during thermal treatment of different coatings, develop novel multi-material coating systems, study the complex correlations between material properties vs. synthesis and processing parameters in real environments. Differential Scanning Calorimetry (DSC) is often used as a standard method to put in evidence different thermal events such as phase transitions, decomposition, oxidation/reduction, nucleation and growth at the substrate/coating interfaces or in coating materials. The present paper aims to review some examples on how DSC may be used to assess the thermal behavior of coatings using standardization tools and developing novel application fields.
\end{abstract}

Keywords: Thermal analysis / nanostructured coatings / phase transitions / metals / intermetallic compounds / ceramics / hybrid materials

\section{Introduction}

Nanotechnology and nanomaterials are considered one of the key-enabling technologies that may fulfill the demands of both traditional and high-tech industrial sectors. Surface modification and coatings offer the possibility to deliver nanostructure materials, able to work in various environmental conditions at sustainable costs compared to bulk materials. The development and understanding of nanostructured coatings - that can withstand simultaneously different external constraints (high or low temperatures, high pressures, high mechanical stresses, high corrosive or oxidizing atmosphere, high electromagnetic fields or fluxes) - open new opportunities in many areas of technology, such as: automotive, aerospace, industrial or military equipment, energy generation and storage, electronics,

\footnotetext{
* e-mail: sbejan@imnr.ro; amotoc@imnr.ro
}

biomedical, chemical and photochemical, metallurgy and machining tools, etc. The need for these nanostructured coatings and their use involve most sectors: transport (automobiles and airplanes that are lighter, with engines that operate at higher temperatures, resulting in improved efficiency), energy (electrical energy storage devices, such as more efficient and long lasting batteries, fission reactors, conventional boilers and stationary turbines that are more efficient, operating at higher temperatures, distribution pipelines for natural gas, hydrogen, ethanol, or other liquid or gaseous fuels that are not subject to failures resulting from corrosion or other chemical reactions), manufacturing (materials, both structural and functional, that can respond to environmental changes and can self-heal and even sense and warn before materials fail, for whatever reason), or health (medical devices with improved biocompatibility and resistance to bacteria).

The main approach to meet these complex requirements must consider integrating different material systems 
Table 1. Application overview of Thermal Analysis methods in coatings assessment.

\begin{tabular}{lccc}
\hline Application range & DSC & TGA & TMA \\
\hline Specific Heat capacity & +++ & + & DMA \\
Thermal stability/decomposition, delamination & +++ & ++ & + \\
Oxidation stability & +++ & +++ & ++ \\
Glass transition temperature & ++ & + \\
Polymorphism & +++ & & + \\
Reaction enthalpy and kinetics & & + \\
Melting and crystallization & & +++ \\
Viscoelastic behavior, elastic modulus & +++ & ++ \\
Softening temperature & +++ & + \\
Expansion, CTE, concentration & + & + \\
Curing behavior of polymers & +++ & + \\
Solid-Solid transitions & & + \\
Phase composition/phase diagrams & & + \\
Purity/thermal analysis of chemicals & & + \\
\hline
\end{tabular}

Notes: +++ recommended methods; + alternative methods.

enabling the gradual optimal adaption of an active surface to the environmental conditions imposed by external constraints [1]. The surface modification may be done using any type of materials: polymers, metals, ceramics, composites or hybrids [2]. Generally, coating processes may principally be divided into two groups: those involving droplet transfer such as plasma spraying, arc spraying, wire-explosion spraying, and detonation gun coating; those involving an atom-by-atom transfer mode such as the PVD processes of evaporation, cathodic arc deposition and sputtering, chemical vapor deposition (CVD), and electrodeposition. Development and innovation in nanostructured coatings is expected to bring also a major improvement in reducing or replacing critical raw materials [3]. In this respect, thermal characterization methods applied in the study and characterization of nanostructured coatings must be regarded as:

- A standard method for assessment of already existing technologies/materials, in order to verify the reproducibility and durability of the nanostructured coating systems. Thermal analysis became one of the simplest and rapid to be used as a standard method for assessing the quality and reproducibility of the coatings;

- A relatively simple and accessible methodology to study and predict the coating process parameters, based on well-established thermodynamic and kinetic models, allowing to preserve the nanostructures during thermal treatment of different novel multi-material coating systems and study the complex correlations between material properties vs. synthesis and processing parameters in real environments. These approaches are fundamental in developing novel nanostructured coating material systems and innovative coating technologies.

Thermal Analysis represents a group of techniques used to measure the physical-chemical properties of a sample during heating, cooling or held at a constant (isothermal) temperature [4]. There are different types of thermal analysis equipment available for thermal assessment of nanostructured coatings.

In Differential Thermal Analysis (DTA) the material under study and an inert reference undergo identical cooling or heating cycles, while recording any temperature difference between sample and reference. Changes in the sample, either exothermic or endothermic, can be detected relative to the inert reference. Thermo-Gravimetric Analysis (TG) measures the mass change of a sample in a specific atmosphere. It may be used for investigating processes such as evaporation, sorption and decomposition. Gases evacuated during the processes may also be analyzed online using hyphenated techniques such as TG-MS and TG-FTIR. Thermomechanical Analysis (TMA) measures dimensional changes of a sample subjected to a defined load, providing information on mechanical module, compliances and damping behavior. Softening, creep or expansion behavior can be observed, depending on the applied load. Dynamic Mechanical Analysis (DMA) allows viscoelastic behavior to be investigated over a wide frequency range. Table 1 briefly shows their applications in research and development, routine analysis and quality control.

The Differential Scanning Calorimeter (DSC) is a fundamental tool in thermal analysis. It can be used in many industries - from pharmaceuticals and polymers, to nanomaterials and food products. The information generated by these instruments is used to understand amorphous and crystalline behaviour, polymorph and eutectic transitions, curing and degree of cure, and other thermal properties used to design, manufacture, and test materials and products.

Differential Scanning Calorimetry, or DSC, is a thermal analysis technique that looks at how a material's heat capacity $(\mathrm{Cp})$ is changed by temperature. A sample of known mass is heated or cooled and the changes in its heat 


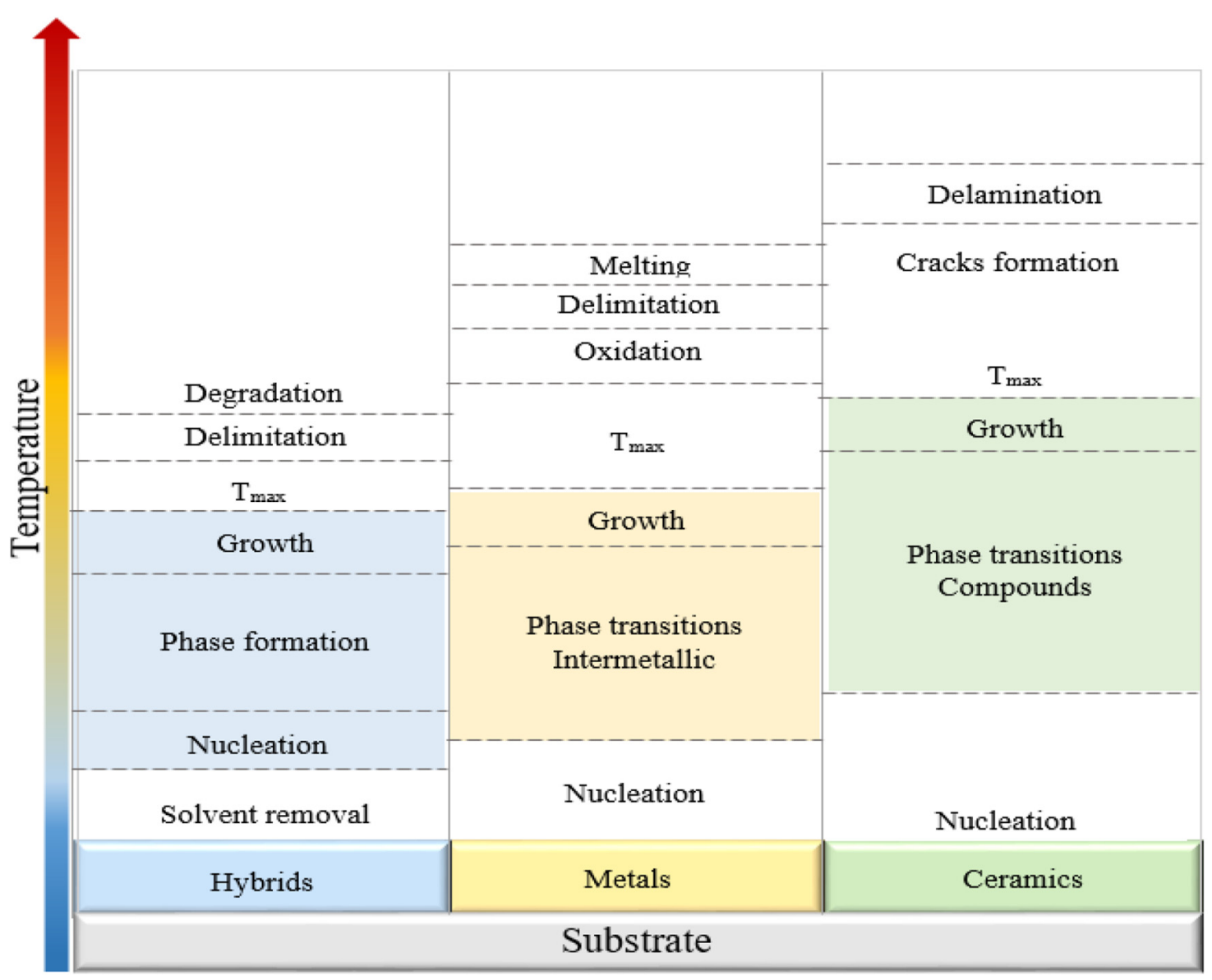

Fig. 1. Main processes during thermal assessment of coatings made of different types of materials.

capacity are tracked as changes in the heat flow. Both DSC and DTA are usually coupled with thermo-gravimetric analysis providing a better evaluation of heat and mass changes during the thermal treatment (DSC-TG; DTATG).

Thermal assessment of coatings should refer to the temperature-driven processes having the major impact on the system stability and properties. In systems consisting of high refractory ceramic coatings on metallic substrates, the major impact of thermal treatment is expected over the metal phase that can melt or oxidize. In this case also interface phenomena may be detected. In coatings systems made from materials with similar thermal behavior, interface phenomena may have a much higher impact.

The main characteristics that differentiate peaks recorded during heating/cooling of a sample are: peak area proportional with the enthalpy of the process, peak direction (depending on the producer of the DSC apparatus; generally, the exothermal processes are considered with negative sign and its position is down and inverse for endothermic peaks), shape (define by onset, peak temperature, end point and inflection), giving information specific for the materials undergoing the thermal process. These characteristics depend not only on the kind of coating system analyzed but also to the heating rate and sensitivity of the equipment. The basic aspects related to these issues are described for example in $[5,6]$.
However, many other information regarding the influence of the deposition methods and parameters on the quality of coatings may be obtained and analyzed using different thermodynamic and kinetic approaches with the help of specific software. The present paper is a review on DSC characterization of nanostructured coatings based on metals, ceramics and hybrid nanomaterials. Figure 1 briefly shows the main processes that may be observed with the help of DSC, during thermal assessment of coatings made of different types of materials. For example, with increasing temperature, different processes - presented in Figure 1-will give a specific peak on the DSC curve that may be further exploited to calculate different thermodynamic and kinetic parameters. For example, at temperatures below $100^{\circ} \mathrm{C}$, solvent removal during thermal treatment of hybrid inorganic-organic coatings will be accompanied by an endothermal peak, proportional to the heat required for liquid-vapour phase transformation of the solvent. Furthermore, a temperature increase will lead to nucleation and crystallization (formation) of new phases in the coating layer, accompanied by releasing the transformation heat, evidenced by an exothermal peak. Additional thermal treatment - at higher temperatures, producing the growth of crystallites from the coating material, will further reduce the free energy of the system with formation of a specific exothermal peak on the DSC curve. 


\section{Nanostructured coatings: sample preparation and system calibration}

\subsection{Sample preparation}

An important aspect specific for thermal characterization of nanostructured coatings by thermal analysis using DSC is related to the very small mass ratio between coated materials and the substrate: any thermal effect associated to the system will be hindered by the substrate heat adsorption. Depending on the sensitivity of the instrument and the enthalpy of reaction, the sample mass necessary to obtain a good signal must be in the range of a fraction of a milligram to about $20 \mathrm{mg}$ at a scanning rate of $5-10 \mathrm{~K} / \mathrm{min}$. In order to increase the signal-to-noise ratio, different strategies may be adopted [7]:

- Removal of the film from the substrate and treating it as a free-standing sample. This method is easier to be applied when the adherence is low and the hardness of the coated material allows to use an adequate mechanical process to remove the film without contamination. Increasing the coatings thickness over a certain value usually leads to a decrease of the coating adherence of the external layers that may be removed for future characterisation. According to US military standard MIL-M-13508C (scotch band method), films and coatings with low adherence may be removed using a cellulose scotch band type L-T-90 that is pressed against film surface and then slowly removed.

- Partial or total removal of the substrate, by different mechanical or chemical (dissolution) processes. The choice of this method depends on the kind of substrate material, with the same concern in avoiding the film contamination and its handling. When mechanical or chemical removal of the substrate is difficult, a convenient solution is to deposit the same material in the same experimental conditions, on a substrate specimen that can be easily removed without affecting the purity of the coating material. These may be done, for example, using small sheets of polymers as substrates, that may be further removed by burning the sample in an oven, at low temperatures. Another method uses sheets of optical glass or Si wafers as substrates, and applying either the scotch band method previously described or manually scratching the surface with a metallic blade, to remove the film, due to the low adhesion force with the substrate. The selection of the removal procedure generally means preliminary tests to identify the most suitable method.

- Fabrication of multi-layered nanostructures to increase the thermal effect and reaction rate with significant amplifying the signal [7]. This is a very useful method to study the interface reactions in the elaboration of complex intermetallic coating systems. The substrate should be selected in such a way to be easily removed.

\subsection{System calibration}

The sample should have direct thermal contact with the bottom of the sample crucible in order to obtain a reliable DSC curve. Different methods may be used for that: heating the sample for softening due to glass transition and performing a second scanning after the sample has been cooled and layered over the bottom of the crucible (this method is not recommended if the first heating scan contains important information that are lost); packing the sample into the sample crucible to ensure good thermal contact (depending on the various shapes of commercially available crucibles); cutting representative parts of films, sheets or membranes into discs according to the diameter of the sample crucible. The linear portion of the DSC curve exhibiting no endothermic or exothermic peak in the presence of a sample is called the sample baseline. It is recommended to scan two empty crucibles under the proposed experimental conditions to check the curvature and noise level of the instrument baseline before analysing the samples, to eliminate the influence of trace amounts of residue condense on the sample holder; moisture condensation or the flow rate variation of the purge gas. In some cases, when during the first heating scan stable products are formed, the line recorded during cooling may be used as baseline.

Standard reference materials are used to calibrate the temperature and energy scale of DSC instruments. Following calibration, the characteristic temperature and the enthalpy associated with a process can be measured for any sample. Temperature calibration is generally carried out using the melting temperature of selected reference metals whose purity is $\geq 99.99 \%$ certified by the International Confederation for Thermal Analysis and Calorimetry (ICTAC) and available through the US National Institute of Standards and Testing (NIST). At least two standard reference materials, whose transition temperatures span the sample transition interval, should be used. Temperature calibration should be performed only in the heating cycle due to significant under-cooling of the metal can occur during the cooling cycle [8].

The enthalpy released or absorbed during a physicalchemical process is an important thermodynamic quantity that may be used to predict the stability of coatings and systems. These enthalpies can be determined from DSC experiments, by integrating the rate of heat flow over the course of the process or a constant-heating-rate experiment according to:

$$
\Delta H=\int_{T 1}^{T 2} \frac{1}{\beta}\left[(d H / d t)_{d a t}-(d H / d t)_{b s l}\right] d T
$$

where $\Delta H$ is the total heat released, $\beta=d T / d t$ is the heating rate, $(d H / d t)_{d a t}$ is the actual sample heat flow rate, $(d H / d t)_{b s l}$ is the baseline heat flow rate and $T_{1}$ and $T_{2}$ are the limits of integration. The values may be calculated as molar enthalpies multiplying the integral $\Delta H$ by the constant $M /\left(m n_{\text {mole }}\right)$, where $M$ is the molecular weight of the product phase, $m$ is the mass of the sample and $n_{m o l e}$ is the number of atoms in one molecule of the compound phase. This enthalpy is typically referenced to a temperature the marks the onset of the reaction. Modern DSC equipment are endowed with software enabling rapid calculation of the transformation enthalpy for each peak. 
Table 2. The mathematical functions $f(\alpha)$ and $g(\alpha)$ for the most important solid state reactions mechanisms [9].

\begin{tabular}{lll}
\hline Reaction mechanism & $f(\alpha)$ & $g(\alpha)$ \\
\hline Reaction order model & $(1-\alpha)^{n}$ & $-\ln (1-\alpha)$, for $n=1$ \\
& & $\frac{1-(1-\alpha)^{(-n+1)}}{-n+1}$, for $n \neq 1$ \\
Homogeneous nucleation and growth (Avrami-Erofeev) & $n(1-\alpha)[-\ln (1-\alpha)]^{(1-1 / n)}$ & {$[-\ln (1-\alpha)]^{1 / n}$} \\
Uni-dimensional diffusion (parabolic law) & $\frac{1}{2 \alpha}$ & $\alpha^{2}$ \\
Bi-dimensional diffusion & $\frac{1}{[-\ln (1-\alpha)]}$ & $(1-\alpha) \ln (1-\alpha)+\alpha$ \\
Tri-dimensional spherical diffusion (Jander equation) & $\frac{3(1-\alpha)^{2 / 3}}{2\left[1-(1-\alpha)^{1 / 3}\right]}$ & {$\left[1-(1-\alpha)^{1 / 3}\right]^{2}$} \\
Tri-dimensional diffusion (Ginstein-Brouhnstein equation) & $\frac{2\left[(1-\alpha)^{-1 / 3}-1\right]}{3}$ & $\left(1-\frac{2 \alpha}{3}\right)-(1-\alpha)^{2 / 3}$ \\
Prout-Tompkins equation & $\alpha(1-\alpha)$ & $\ln \frac{\alpha}{1-\alpha}$ \\
Power law & $n(\alpha)^{(n-1) / n}$ & $\alpha^{1 / n}$ \\
Exponential law & $\alpha$ & $\ln \alpha$ \\
\hline
\end{tabular}

\section{Kinetics investigations methods}

Starting from the DSC measurements, the kinetics of different processes may be investigated, aiming to determine the rate equation and the corresponding activation energy, reaction mechanism and predict the reaction behaviour for complex time-temperature profiles of DSC curves. The modern DSC devices with high sensitivity and software allow rapid analysis of the process kinetics within less time compared to the classical chemical methods using quasi-isothermal experiments. The description of the possible reaction mechanism, by a formal kinetic model is presently the most flexible and fastest solution to determine the so called "kinetic triplet" (consisting of the pre-exponential factor, activation energy and reaction order).

Considering that the kinetic of a process given by the transformation degree defined by the equation

$$
v=\frac{d \alpha}{d t}=k(T) f(\alpha)
$$

where $\alpha$ is the transformation degree (the ratio between the area of a DSC peak at a given time and temperature to the total area of the peak), $t$ is the time and $T$ the absolute temperature, and

$$
k(T)=A \exp \left(-\frac{E}{R T}\right)
$$

where $A$ is the rate constant pre-exponential factor, $E$ is the activation energy and $R$ is the universal gas constant $\left(8.314472 \mathrm{JK}^{-1} \mathrm{~mol}^{-1}\right)$, the procedure consists in calculating the transformation degree best fitting the experimental values for the specific peak using different reaction models according to the generalized equation

$$
f(\alpha)=\alpha^{m}(1-\alpha)^{n}
$$

using the corresponding integral conversion function

$$
g(\alpha)=\int_{0}^{\alpha} \frac{d \alpha}{f(\alpha)}
$$

where $m$ is a constant parameter and $n$ the reaction order. Since all the reactions of interest in nanostructured coatings studies are practically solid-state processes, the reactions models that can be used to calculate the kinetic triplet are presented in Table 2 .

A well-known method for rapid estimation of the activation energy of a process is the Kissinger equation:

$$
\ln \frac{\beta}{T_{\max }^{2}}=\frac{E}{R T_{\max }}+\ln \left(A R n\left(1-\alpha_{\max }\right)^{n-1}\right)
$$

where $\beta$ is the experimental heating rate of the DSC apparatus and $T_{\max }$ is the maximum temperature of the peak corresponding to a transformation process. A linear plot of $\ln \frac{\beta}{T_{\max }^{2}}$ vs. $\left(1 / T_{\max }\right)$ should be a line having the slope equal to the activation energy. 


\section{Thermal assessment of nanostructured coatings}

\subsection{Thermal assessment of nanostructured metallic and intermetallic coatings}

Metallic and intermetallic nanostructured coatings on different substrate materials play a major role in many modern technologies. Critical applications include optic and optoelectronics, semiconductor devices (for example in solar energy panels or sensors) as well as abrasion/ corrosion resistance [10]. Both physical and chemical processes (PVD, CVD) from vapor phase are largely used to produce such coatings. Generally, more than one layer and material are used to obtain the desired functionality. Thermal analysis of these types of coatings is an essential tool for:

- assessment deposition process for further validation (ensures there is no un-expected or un-desired phase transformation during coating process development);

- Product assessment (the thermal stability of the coating is reached in the temperature range required by specific application and no internal stress is producing un-desired delamination of the film).

Both thermodynamic and kinetic approaches are essential tools to asses these types of coatings and the diffusion and mass transfer processes leading to nonequilibrium phases may be evidenced.

The number of such type of metallic systems is practically un-limited, depending on the number of components, phases, doping elements and their ratio. A review article on the application of DSC concerning the use of thin films deposition as a tool to study the thermodynamics and kinetics of thin film reactions was presented in [7]. The intermixing of $\mathrm{Ti}$ and $\mathrm{Al}$ profile may be estimated from the smooth composition profile approximation:

$$
\begin{array}{r}
c(x)=1-\exp \left(-\frac{\ln 2}{\omega} x\right) \quad 0 \leq x \leq \frac{\Lambda}{4} \\
c(x)=-1+\exp \left(\frac{\ln 2}{\omega} x\right) \quad-\frac{\Lambda}{4} \leq x \leq 0
\end{array}
$$

where $\Lambda$ is the multilayer period length, $c(x)$ is the composition at a distance $x$ from the interface and $2 \omega$ defines the thickness of the intermixed layer. $c(x)$ is equal to +0.5 at $\omega$ and -0.5 at $-\omega$.

The enthalpy released during isothermal treatment of different nanostructured coatings may be used to calculate the activation energy of grain growth by assuming an Arrhenius temperature dependence for the rate constant according to

$$
k_{g}=k_{g 0} e^{-\Delta H g /\left(k_{B} T\right)}
$$

where $k g$ is the grain growth rate constant, $k g_{0}$ is the preexponential factor of the rate constant, $\Delta H g$ is the activation energy of grain growth, $k_{B}$ is the Boltzmann constant and $T$ is the absolute temperature. As an example,

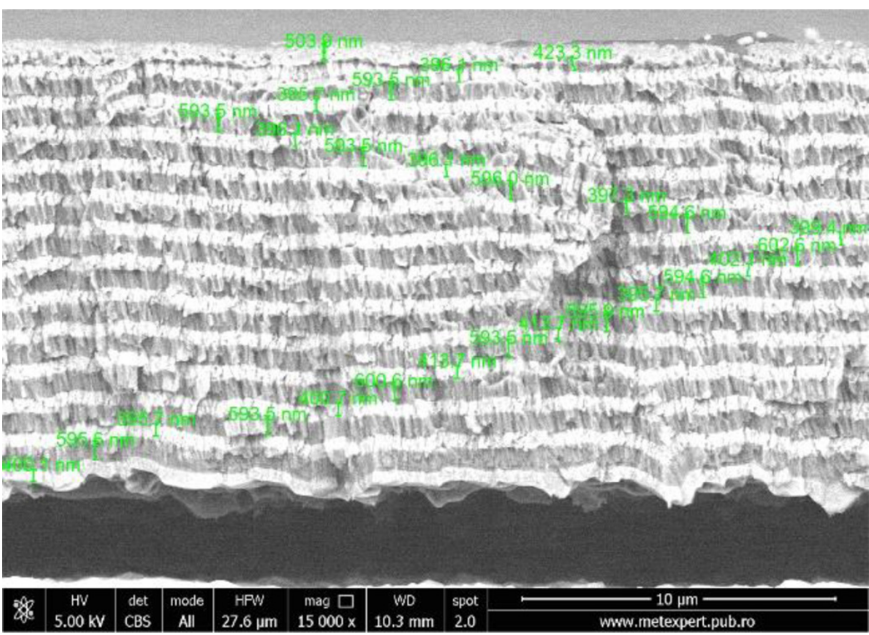

Fig. 2. SEM picture of EB-PVD multi-layered Ti-Al nanostructured coatings with periodical thickness of each film in the range $400-500 \mathrm{~nm}$.

for thin nanostructured coatings based on Ge-Sn alloys of interest in semiconductor devices, this approach gives an activation energy of grain growth around $0.5 \mathrm{eV}$, lower than values calculated by other methods [7]. During nanostructured coatings fabrication, a large variety of nonequilibrium phases may be obtained due to the kinetics limiting factor, leading to structural instabilities. One can also investigate reactions that are driven by chemical and structural instabilities by depositing films with multiple layers of different compositions. Multi-layered films have an ideal architecture for studying the formation of intermetallic phases from pure elements. By decreasing the multilayer period, one can increase the density of interfaces at which the nucleation reaction begins while by increasing it the one-dimensional growth may be enhanced. Here some examples on how thermal analysis (mainly DSC) may be used to assess metallic nanostructured coatings are summarized.

\subsubsection{Formation of intermetallic compounds}

Thermal assessment of nanostructured coatings from the Ti-Al system plays an important role in modern electronic junctions. Beside solid solutions, intermetallic compounds $\mathrm{TiAl}_{3}$ and $\mathrm{TiAl}$ are formed according to equilibrium phase diagram. The deposition of multilayered Al-Ti coatings with atomic ratio 1:3 and periodic thickness of each films in the range $400-500 \mathrm{~nm}$ obtained by electron-beam physical vapour deposition (EB-PVD) on optical glass is presented in Figure 2.

The multi-layered coatings were removed from the substrate and DSC was performed in $\mathrm{Ar}$ atmosphere at heating rates $3,5,7$ and $10^{\circ} \mathrm{Cmin}^{-1}$ with corresponding peaks at $399.176,407.828,423.961$ and $423.4866^{\circ} \mathrm{C}$ respectively (Fig. 3). The DSC results show only the characteristic peak of the intermetallic TiAl compound and no other thermal event (e.g. melting of $\mathrm{Al}$ ) take place in the temperature range $20-1000{ }^{\circ} \mathrm{C}$, proving it is the single intermetallic compound formed in the EB-PVD process. 


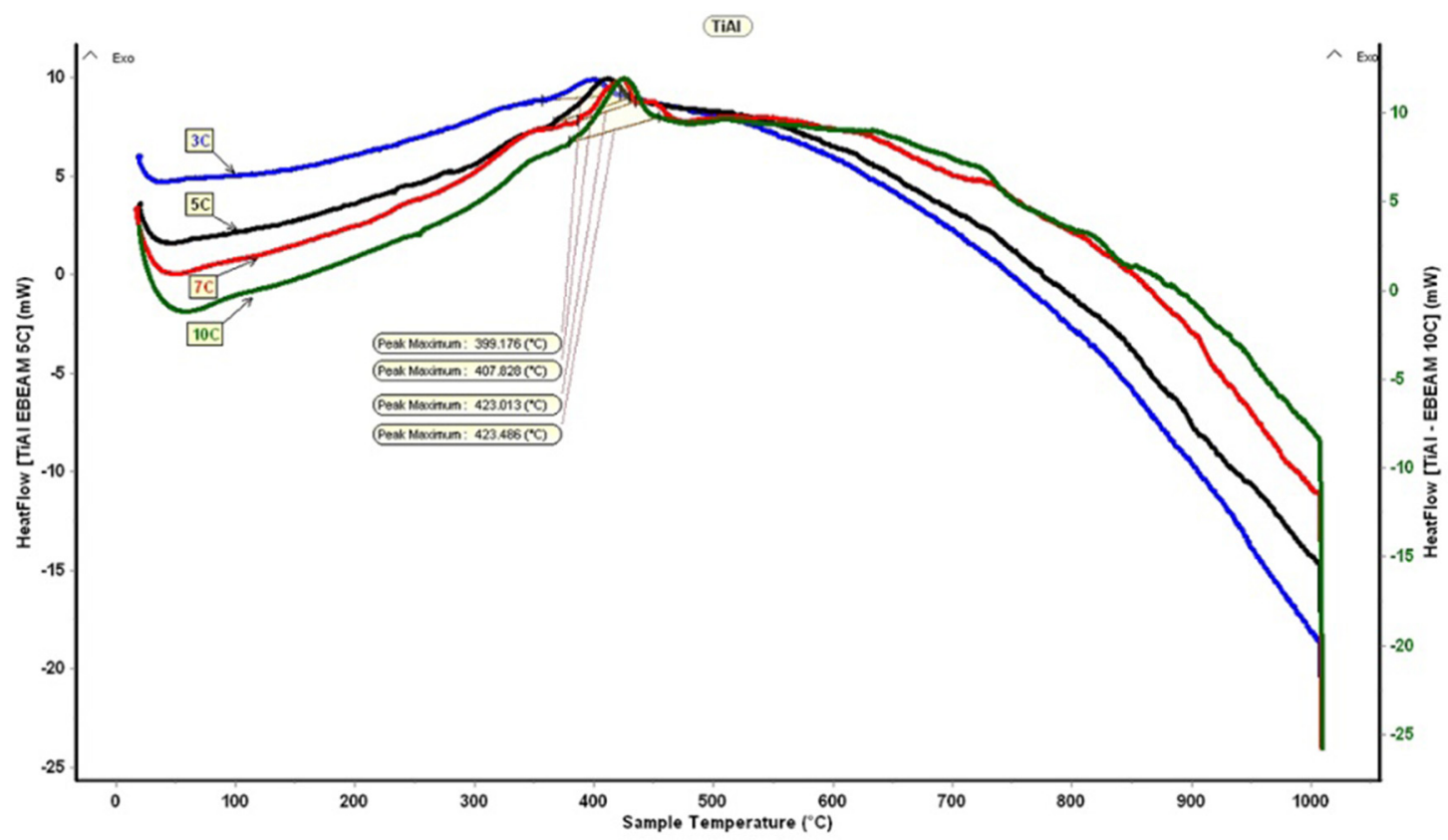

Fig. 3. DSC curves for heating rates $3,5,7$ and $10{ }^{\circ} \mathrm{Cmin}^{-1}$ of EB-PVD multi-layered TiAl nanostructured coatings.

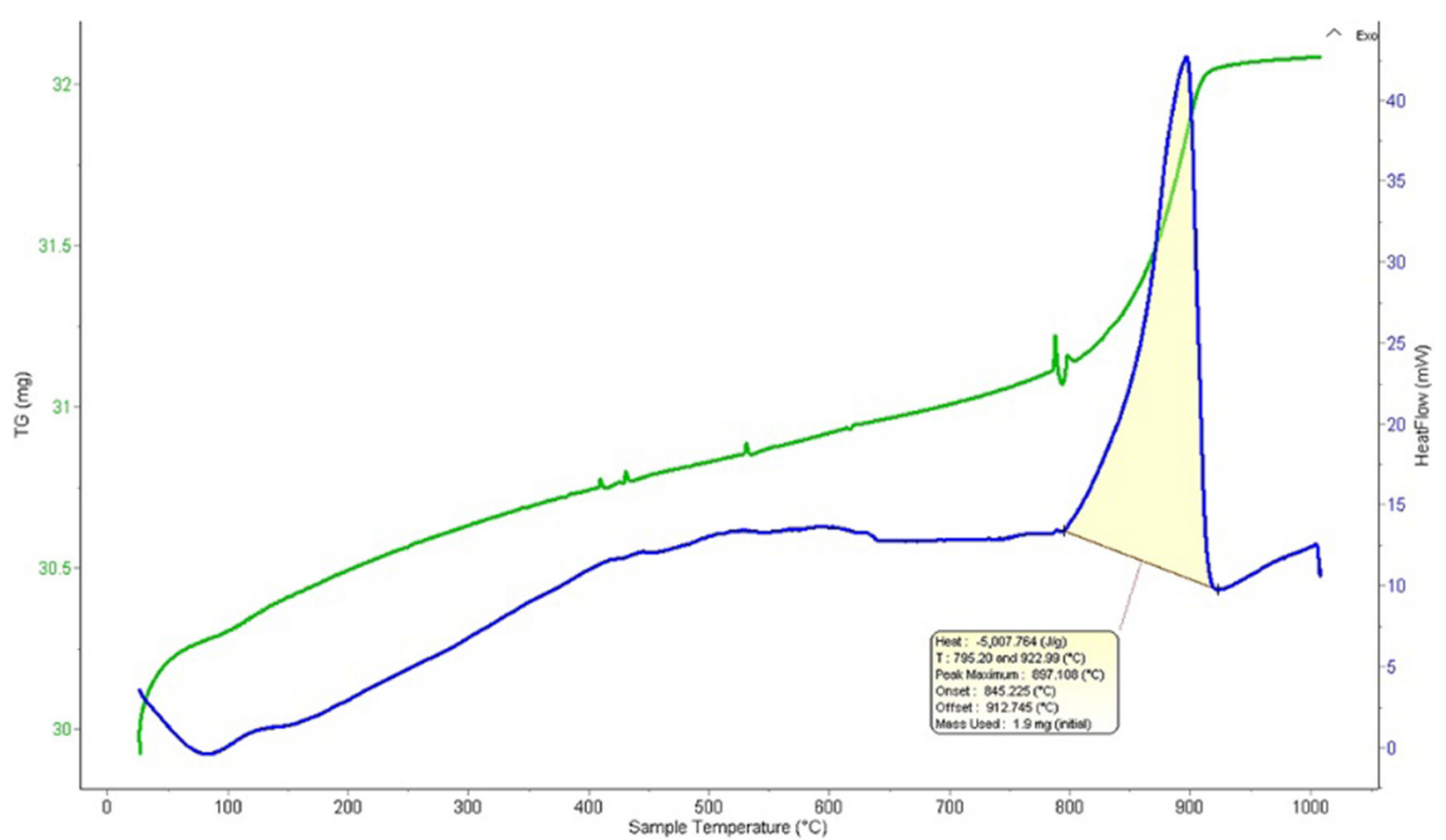

Fig. 4. DSC curves for heating rate $10{ }^{\circ} \mathrm{Cmin}^{-1}$ of EB-PVD multi-layered $\mathrm{TiAl}_{3}$ nanostructured coatings at heating rate $10{ }^{\circ} \mathrm{Cmin}{ }^{-1}$.

The activation energy of the TiAl intermetallic compound formation was estimated around $143.6 \mathrm{~kJ} \mathrm{~mol}^{-1}$, close to $158.9 \mathrm{~kJ} \mathrm{~mol}^{-1}$ previously reported in [11].

When Ti:Al atomic ratio of the coating is changed to $1: 3$ the compound $\mathrm{TiAl}_{3}$ is formed in the coating process and the characteristic exothermal peak corresponding to $\mathrm{TiAl}_{3}$ compound is observed at much higher temperatures around $891^{\circ} \mathrm{C}$ (Fig. 4), in good agreement with those from the corresponding phase diagram.
Thermal analysis of Al-Ni multilayered coatings for energetic applications obtained by RF magnetron sputtering was done by DSC to assess the energy released during exothermal reactions for the formation of corresponding intermetallic compounds [12]. The heat released depends on the bilayer thickness of the coatings, increasing from $389.43,396.69$ and $409.93 \mathrm{Jg}^{-1}$ for thicknesses of 50,100 and $200 \mathrm{~nm}$ respectively. Compared to the theoretical heat reaction value of $1390 \mathrm{Jg}^{-1}$ it results that heat loss 


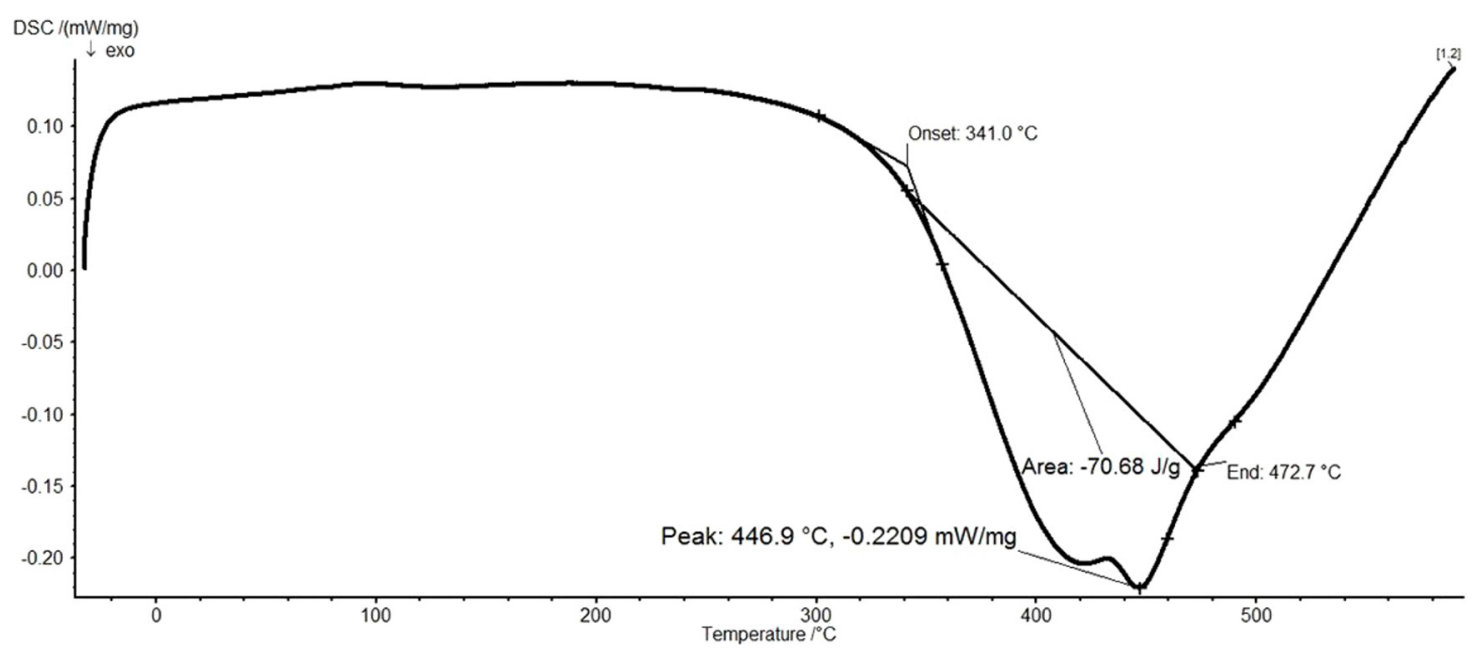

Fig. 5. DSC picture of a $\mathrm{Ni}-\mathrm{Ti}$ sample showing formation of $\mathrm{NiTi}_{2}$ intermetallic phase.

decreases with increasing layers thickness and thus the overall thickness may be optimized to obtain the best energetic values for desired application.

\subsubsection{Phase transitions}

Complex metallic nanostructured coatings undergoing phase transitions during processing, manufacturing and under service, play an important role in applications such as shape memory alloys coatings. Ti-Ni system is one of the major systems with shape memory behavior due to the austenitic to martensitic phase transition. The near equiatomic Ni-Ti alloys (known under commercial name nitinol) have unique shape memory and super-plastic properties and also excellent bio-mechanical and corrosion resistance behavior and are currently used in different types of modern medical implants and it is possible to control the martensitic to austenitic transition temperature by controlling the Ni:Ti ratio. The formation of unwanted $\mathrm{NiTi}_{2}$ or $\mathrm{Ni}_{3} \mathrm{Ti}$ intermetallic compounds may be rapidly assessed by DSC. The enthalpy value of the exothermal peak in Figure $5\left(70.68 \mathrm{~J} / \mathrm{g}\right.$ at $\left.446.9^{\circ} \mathrm{C}\right)$ corresponds to the calculated enthalpy of formation of $\mathrm{NiTi}_{2}$.

An important issue is to assess the influence of the annealing time and temperature on the starting and end temperatures of martensitic transformation temperature and austenitic transformation temperature in nanostructured coatings by analyzing the heat flow during heating and cooling by DSC method [13].

As recent examples, functionally graded shape memory coatings, deposited by radio frequency magnetron sputtering and subsequent annealing [14], Ti-Ni-Zr thin films obtained by magnetron sputtering [15], $\mathrm{Cu}-\mathrm{Zn}-\mathrm{Sn}$ shape memory alloys with Sn compositional range 13.7-46.3 wt.\% Sn that were fabricated by electrodeposition route [16], have been optimized using DSC measurements.

$\mathrm{Ni}-20 \% \mathrm{Sn}$ nanostructured coatings consisting of $\mathrm{Ni}$ solid solution, $\mathrm{Ni}_{3} \mathrm{Sn}, \mathrm{Ni}_{3} \mathrm{Sn}_{2}$ and metastable $\mathrm{NiSn}$ intermetallic phase have been deposited by high velocity cold spraying onto metallic substrates. The soft or hard intermetallic nature of NiSn intermetallic phases plays a crucial role in controlling the friction and wear properties of coated surfaces [17]. DSC analysis was used to assess the presence of different equilibrium phases. The DSC-TG curve from Figure 6 shows that hard equilibrium $\mathrm{Ni}_{3} \mathrm{Sn}$ phase is presented and the working temperature must be limited in order to avoid formation of the low temperature LT- $\mathrm{Ni}_{3} \mathrm{Sn}$ (characteristic peak temperature $\sim 951^{\circ} \mathrm{C}$ ) and its transformation to high temperature $\mathrm{HT}-\mathrm{Ni}_{3} \mathrm{Sn}$ (characteristic peak temperature $\sim 1137^{\circ} \mathrm{C}$ ).

\subsection{Thermal assessment of nanostructured inorganic and hybrid coatings}

Inorganic (oxide and non-oxide ceramic) and hybrid nanostructured coatings on different substrate materials play also a major role in many new applications related to optoelectronics, semiconductor devices, piezoelectric devices and transducers, biocompatible implants in regenerative medicine, corrosion and abrasion enhanced surfaces, etc. Besides physical and chemical processes (PVD, CVD) used to produce such coatings, chemical methods from solution become more and more important to obtain new coating systems with preserving the nanostructure during processing and utilization. Thermal analysis of inorganic and hybrid coatings is an essential tool for the assessment of:

- Validation of the new developed coating processes. Especially for solution coatings processes (spin-coating and sol-gel from organo-metallic compounds using organic solvents or hydrolytic precipitation or electrochemical/electrophoretic deposition), the reaction chemistry and pathways associated to the elimination of solvent compounds, nucleation and crystallization form solution are the key steps in obtaining the desired nanostructures and properties [18]. Thermal analysis provides a simple and rapid way to control and predict the thermodynamics and kinetics of these processes;

- Product validation: the thermal stability of the coating is maintained in the required temperature range for the specific application, producing the desired crystalline 


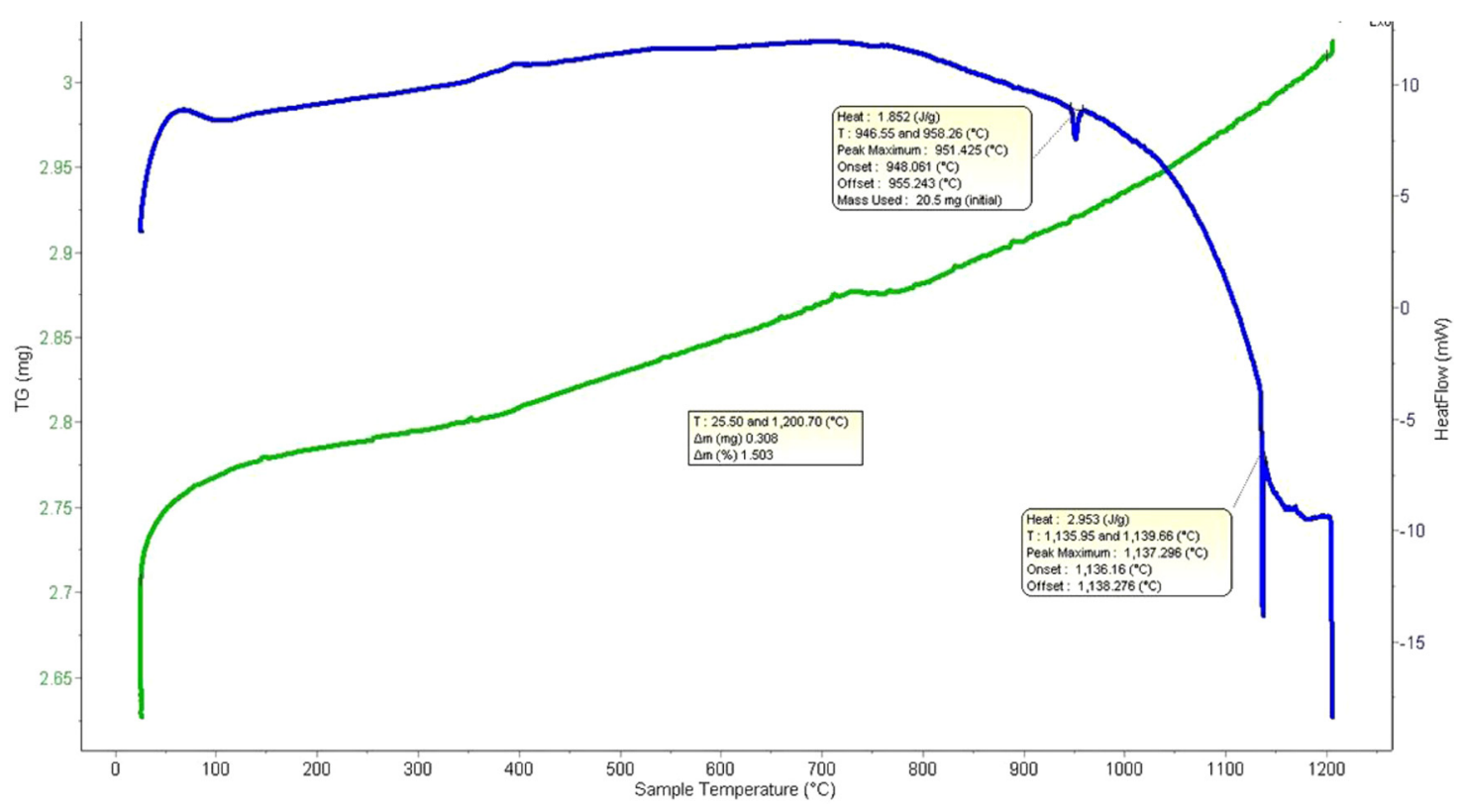

Fig. 6. DSC-TG analysis of cold-sprayed Ni-20\% Sn nanostructured coatings.

phase and avoiding any other subsequent processes producing decomposition, internal stress and delamination of the film.

The thermodynamic and kinetic assessment of these types of coatings must highlight also any interactions between components or degradation of the substrate due to film annealing. Some examples are: optimization of multiferroic $\mathrm{Bi}_{5} \mathrm{FeTi}_{3} \mathrm{O}_{15}$ (BFTO) films with uniform grain sizes $\sim 300 \mathrm{~nm}$ on $\mathrm{Pt} / \mathrm{Ti} / \mathrm{SiO} 2 / \mathrm{Si}$ wafer substrates obtained by sol-gel method [19]; $\mathrm{Cu}_{2} \mathrm{ZnSnS}_{4}$ (CZTS) nanostructured films prepared by spin-coating followed by thermolysis and annealing on Mn-coated soda lime glass substrates for optoelectronic applications [20]; inorganic and hybrid (organically modified inorganic) films based on the hydrolysis and condensation of metal alkoxides, Si-(OR) $\mathrm{n}$ to obtained coatings with good adhesion and corrosion protection [21]; hybrid thin films based on $\mathrm{ZnO}$ and $\mathrm{Ag}$ : $\mathrm{ZnO}$ nanoparticles dispersed in chitosan and incorporated in poly(methyl methacrylate) (PMMA) matrix obtained by a modified sol-gel method [22]; Yttria-stabilized zirconia (YSZ) thin films play an important role as electrolyte material for solid oxide fuel cells obtained from zyrconil oxalate [23].

\subsubsection{Inorganic coatings}

Titanium Dioxide has important photo-catalytic properties and applications, with efficiency depending on the crystallite structure, sizes and morphology, the best results corresponding to the stabilization of anatase lattice. The energy for transformation of anatase to rutile nanomaterials can be assessed by DSC analysis from the corresponding exothermal peak; as an example, in the hydrothermal route, this energy is in the range 495$714.7 \mathrm{Jmol}^{-1}$ depending on the heating rate [24]. The properties of $\mathrm{TiO}_{2}$ nanostructured films may be drastically modified and controlled via doping with different elements. For example, Co-doped $\mathrm{TiO}_{2}$ (CTO) materials have received a high interest due to their ferromagnetic properties with high potential in spintronic and magnetic device applications [25,26], being strongly dependent on doping concentration and distribution and the presence of lattice defects such as oxygen vacancies. Consequently, obtaining of nanostructured coatings allowing stabilization of non-equilibrium phases is expected to strongly influence the ferromagnetic and spin dynamics properties of these materials. The investigation of the crystallization of $\mathrm{TiO}_{2}$ nanostructured films doped wit up to $5 \%$ Co obtained by a hydrothermal-electrochemical method was done by DSC method with the aim to optimize the deposition process and study the activation energy of the crystallization. Figure 10 presents the DSC lines of undoped and $\mathrm{TiO}_{2}$ doped with 2.5 and $5 \%$ wt.\% Co respectively (Fig. 7).

Three groups of peaks can be observed with increasing temperature: the first is related to elimination of absorbed water, the second elimination of the internal crystallization water and third one is related to crystallization of $\mathrm{TiO}_{2}$ anatase. The kinetic triplets for the third crystallization peak were calculated starting from the DSC results and different kinetic mechanisms. These results show a changing of crystallization mechanism of Co-doped $\mathrm{TiO}_{2}$, the reaction order $2 / 3$ corresponding to a tridimensional diffusion changing to a reaction order 1 for undoped $\mathrm{TiO}_{2}$ corresponding to a homogenous nucleation and growth. These results allow further optimization of the process in terms of selecting the temperature and time desired to obtain a programmed crystallization degree of the nanostructured coating.

Silicon doped titanium dioxide nanoparticles $\left(\mathrm{TiO}_{2}\right.$ with $2-20$ wt.\% $\mathrm{SiO}_{2}$ ) prepared by a soft chemical route have been coated on leather surface as alternative to 


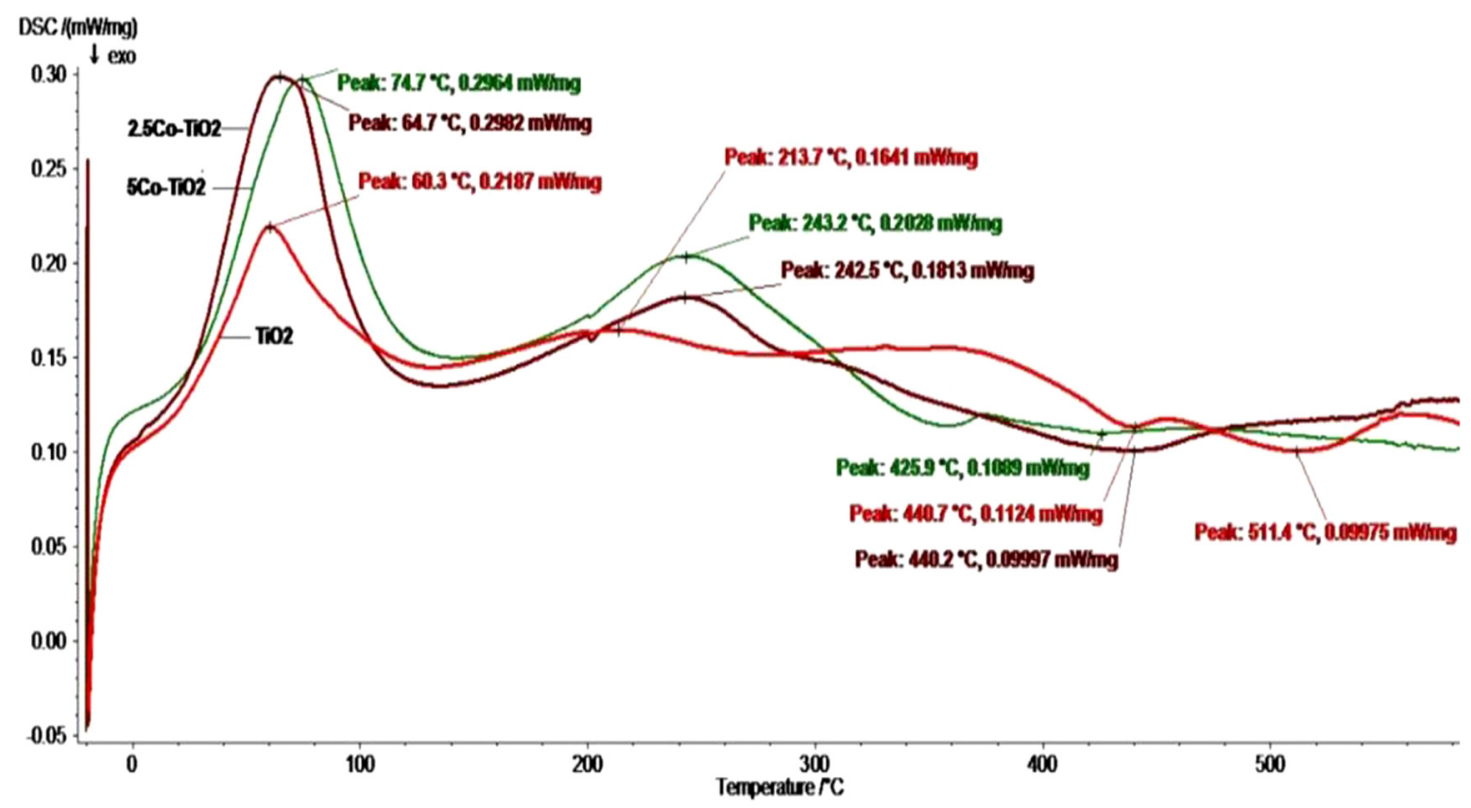

Fig. 7. DSC lines of un-doped and $\mathrm{TiO}_{2}$ doped with 2.5 and $5 \%$ wt. $\%$ Co respectively.

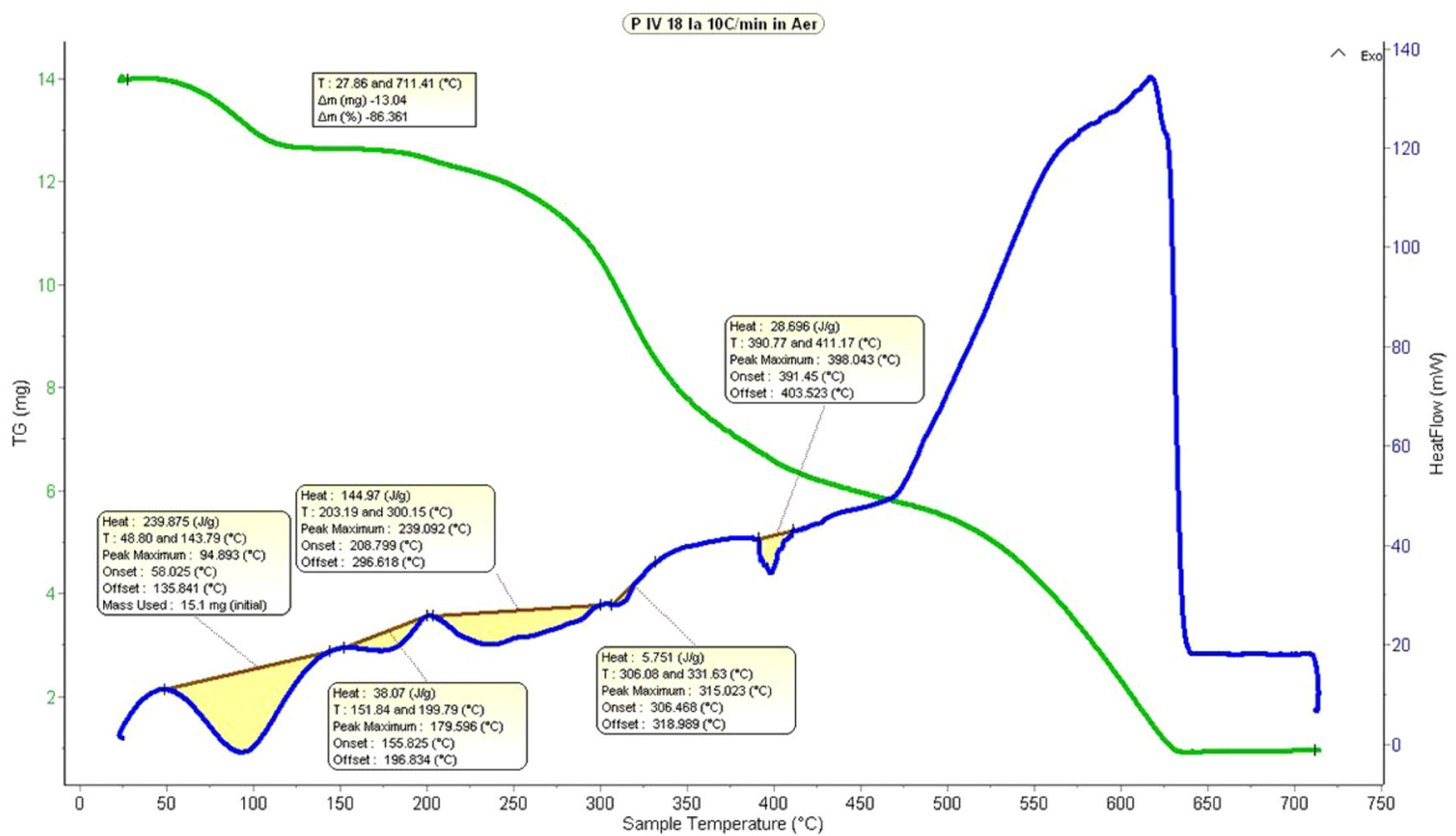

Fig. 8. DSC-TG spectra of $\mathrm{TiO}_{2}-20$ wt. $\% \mathrm{SiO}_{2}$ hybrid coatings.

halogen-based flame retardants and dry-cleaning solvents. The DSC-TG spectra of $\mathrm{TiO}_{2}-20$ wt. $\% \mathrm{SiO}_{2}$ are presented in Figure 8.

Although the standard method for flame retardants characterisation is cone calorimetry, DSC-TG method enables to calculate the activation energy of coated leather degradation by Kissinger method and furthermore to assess the optimal coating conditions [27]. Such type of smart coatings responding to multiple external stimuli (light, dirt, pH changes, temperature, aggressive liquids, biofoulant, impact, fatigue etc.) have demonstrated outstanding barrier properties with scratch resistance, in-situ healing, superhydrophobicity, superoleophilicity, high optical transmission, thermal stability (controlling degradation and glass transition), and resistance to corrosion, resulting in extended service life of the coatings and the protected metallic materials [28,29].

\subsubsection{Hybrid inorganic-organic coatings}

Carbon nanotubes (CNTs) and graphite may be used as additives for different polymer coatings formulations to provide different properties, among them electrical and thermal conductivities and/or mechanical properties. 


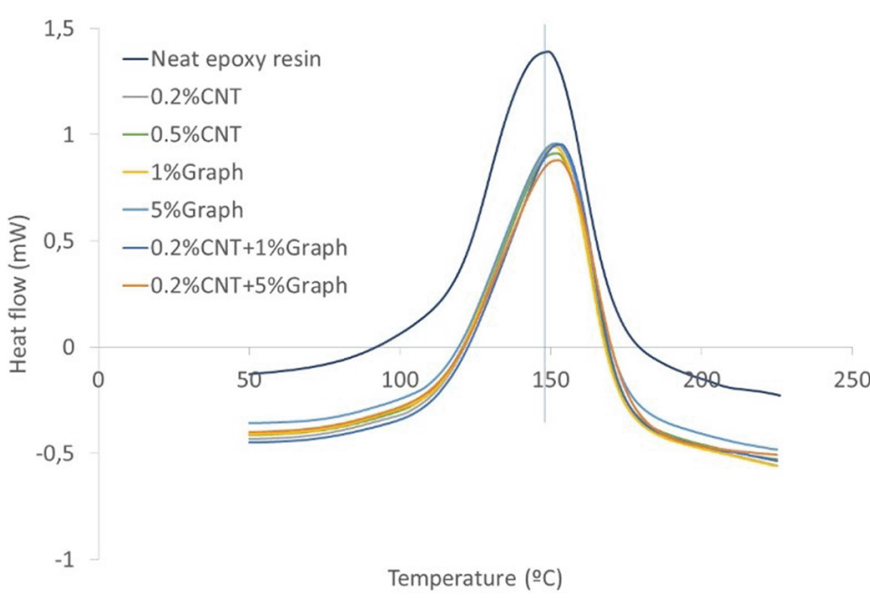

Fig. 9. Effect of CNT and/or Graphite on thermal curing of epoxy resin by DSC.

In particular, for epoxy resins, resultant properties of composites incorporating carbon-based materials have been demonstrated to be dependent on the ratio of filler/matrix, orientation and their dispersion degree within the matrix. These resins have good stiffness, strength, dimensional stability, and chemical resistance and durability which makes them useful for a great variety of industrial applications, especially in the electronics, automotive, aeronautics or aerospace industries.

However, incorporation of carbon-based materials to epoxy resins may affect the curing process of the epoxy resin and/or the crosslinking degree and consequently thermal and mechanical properties of the epoxy resin. DSC has been used to evaluate both the curing process and the transition temperature $\left(\mathrm{T}_{\mathrm{g}}\right)$ of different formulations of epoxy resin containing CNTs and/or graphite, fillers with different morphology, surface area and aspect ratio [30].

Figure 9 shows the curing process for the different formulated epoxy resin with CNTs and/or graphite. There are not noticeable differences identified in the curing process of the epoxy resin containing the different fillers. However, some differences are produced in respect to the neat epoxy resin, which requires higher amount of energy for the curing process. Nevertheless, the curing peak temperature is lower than the peak temperature of the differently filled epoxy resins.

Additionally, the glass transition temperature of a polymer coating is often related to the curing of the epoxy resin, as well as to the interfacial interaction between epoxy and the additives and the crosslinking degree. As an example, Table 3 shows that the incorporation of CNTs favours the crosslinking of the polymeric chains, increasing the transition temperature $\left(\mathrm{T}_{\mathrm{g}}\right)$.

Because the nanotubes are nanometer sized with a high aspect ratio, the reinforcement and increased crosslinking of the epoxy resin is obtained at very low CNT content.

This result is increased with the incorporation of $1 \%$ Graph, which allows a higher crosslinking of the polymeric chains and an increased interaction between the filler and
Table 3. $\mathrm{T}_{\mathrm{g}}\left({ }^{\circ} \mathrm{C}\right)$ of epoxy resin incorporating $\mathrm{CNTs}$ and/or Graphite by DSC.

\begin{tabular}{ll}
\hline Sample & Tg $\left({ }^{\circ} \mathbf{C}\right)$ \\
\hline Neat epoxy resin & 188.9 \\
Epoxy resin $+0.2 \%$ CNT & 195.6 \\
Epoxy resin $+0.5 \%$ CNT & 199.9 \\
Epoxy resin $+1 \%$ Graphite & 202.0 \\
Epoxy resin $+1 \%$ Graphite & 187.9 \\
Epoxy resin $+0.2 \%$ CNT $+1 \%$ Graphite & 204.2 \\
Epoxy resin $+1 \%$ Graphite & 169.6 \\
\hline
\end{tabular}

the polymer chains. However, higher \% graphite (5\%) produces a reduction on the crosslinking, either when only $5 \%$ graphite is incorporated or when incorporated in the mixture with $0.2 \%$ CNT. Therefore, DSC may be used as a technique to evaluate the influence of additives on coatings formulations as well as to qualitatively establish their interaction and compatibility within the polymer chains.

The attachment of nanoparticles has been proposed as one method for potential development of super-hydrophobic surfaces. Nanostructured zinc oxide coating, developing multi-textured flower-like habit on the carbon surface, is a good candidate for drastic reduction of contact angle and surface energy [31]. Hydrothermal-electrochemical method has been successfully used to obtain $\mathrm{ZnO}$ nanostructured coatings on porous carbon materials [32]. DSC-TG method (Fig. 10) has been successfully used to assess the optimal thermal treatment of initial Zinc Carbonate Hydroxide Hydrate films formed during hydrothermal process to produce nanostructured $\mathrm{ZnO}$ coating with good surface coverage and adhesion.

\subsection{Thermal assessment of nanostructured high temperature functionally graded coatings}

Advanced thermal protection systems (thermal barrier coatings and other types of functionally graded materials) are needed in many applications to mitigate effects of high temperature usually associated with high corrosion and erosion problems in aeronautics, automotive or energy co-generation systems. These systems require coatings that will protect structures against temperatures in excess of $1200^{\circ} \mathrm{C}$, enabling them to maintain tensile strength and oxidation resistance. Thermal protection systems must be engineered to have the following qualities: adherent and continuous to provide erosion resistance and limit the mechanisms of evaporation, prevent oxygen permeation through the coating and reduce the diffusion of oxygen to the substrate, mechanically compatible to resist coating spallation due to thermal expansion mismatch during extreme thermal heating, easily processed so that they can be made reproducibly and reliably [33,34]. For such types of materials and coatings (consisting mainly in high refractory oxides, carbides or borides), the previously described thermal analysis methods are un-adequate in assessing 


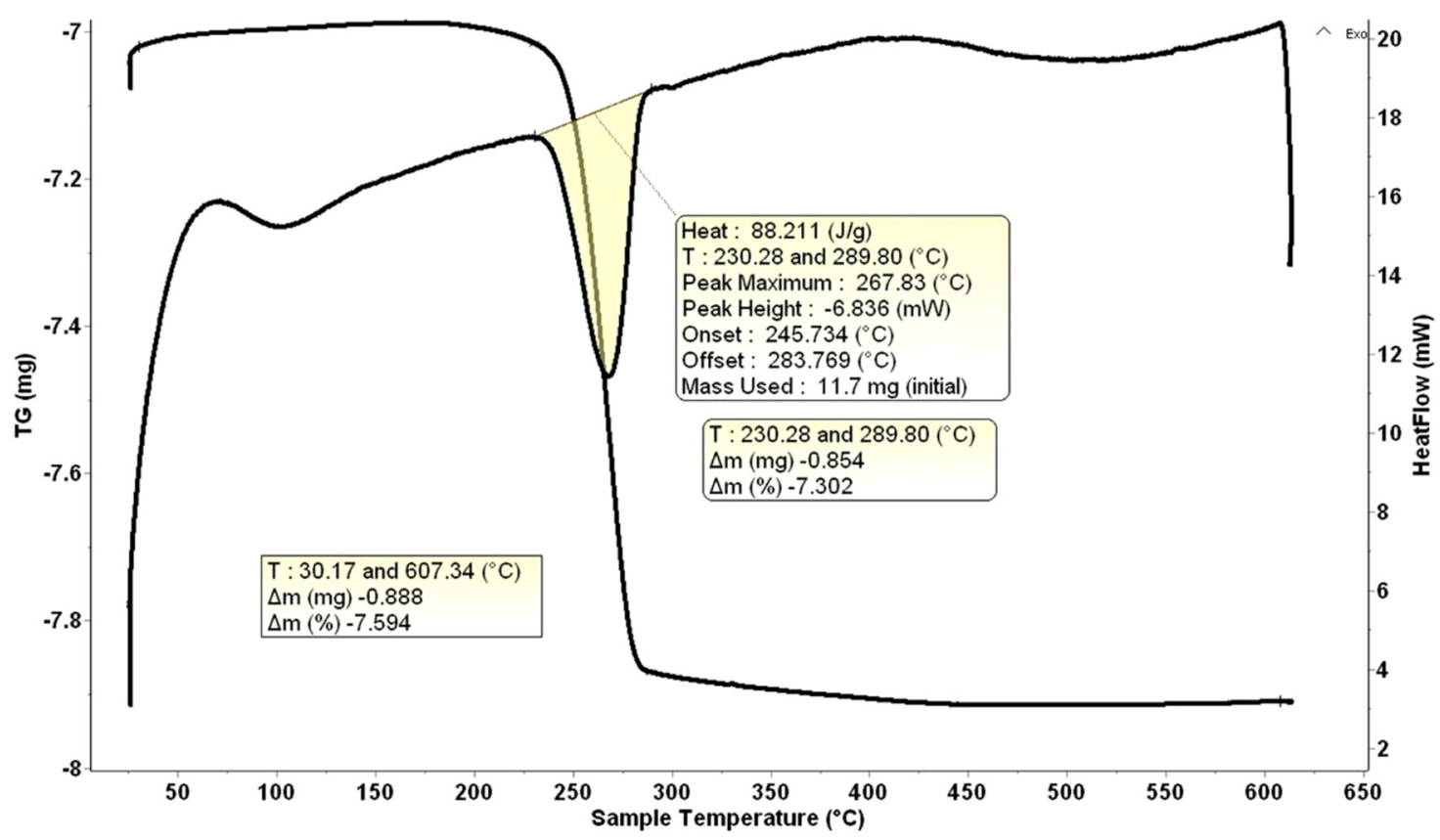

Fig. 10. DSC-TG curve showing decomposition of Zinc Carbonate Hydroxide Hydrate with formation of ZnO on porous carbon surfaces.

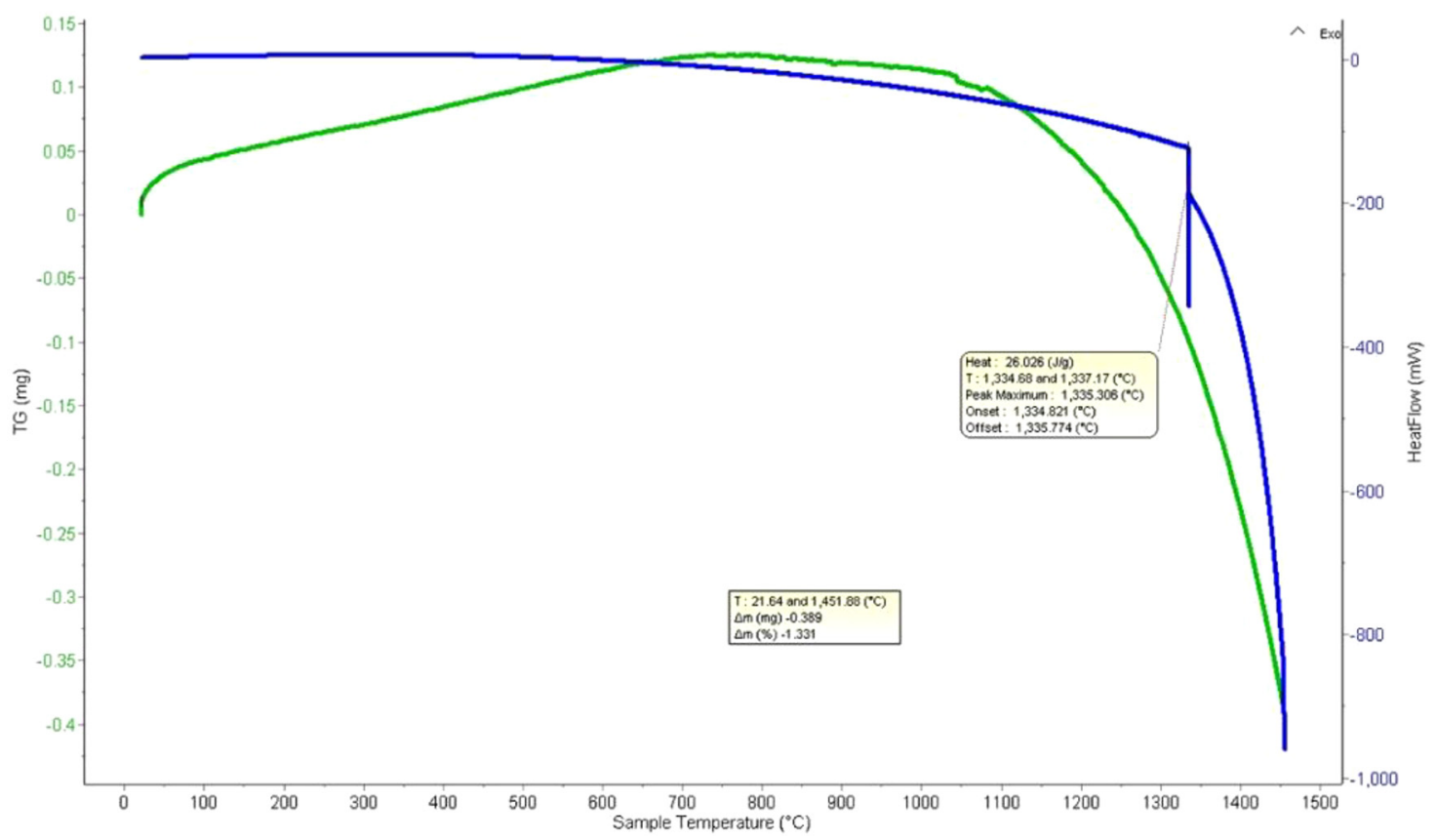

Fig. 11. The DSC-TG curve for yttria-doped zirconia coatings on graphite substrate.

the thermo-mechanical stability due to very high structure stability, high melting point and high thermal conductivity.

However, DSC coupled with thermogravimetric analysis may still provide information about the oxidation or reduction processes at the substrate-coating interfaces. As shown in Figure 11 a total mass loss of $\sim 1.33 \%$ in the TG curve at temperatures above $1050{ }^{\circ} \mathrm{C}$ may be observed due to the formation of volatile $\mathrm{CO}_{2}$ during oxidation of graphite substrate oxidation coated with $200 \mathrm{~nm}$ yttriadoped zirconia film by vacuum electron beam deposition method (EBPVD). For coatings with the same composition and thickness on metallic $\mathrm{Nb}$ foil, the oxidation of the substrate at temperatures leads to the formation of an oxide film, proved by a total mass increase of $\sim 1 \%$ in the TG curve (Fig. 12). 


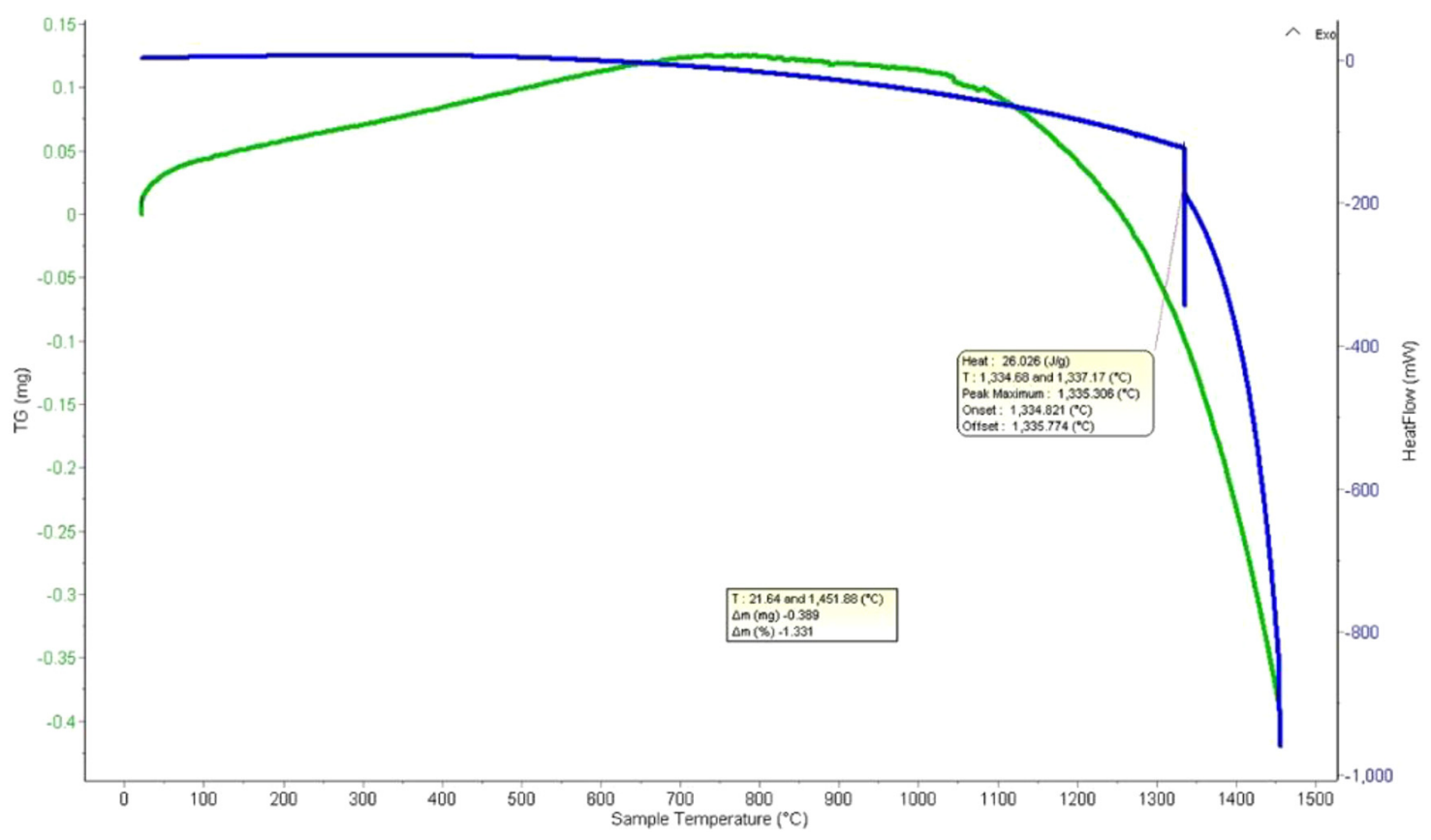

Fig. 12. The DSC-TG curve for yttria-doped zirconia coatings on Nb substrate.

Different additional testing systems must be done by corroborating the results of DSC with complex investigations of the interface processes in the multilayered protective coatings to reveal the structural and compositional modifications gradually induced by thermal shock testing followed by advanced investigations of analytical electron microscopy (TEM, SEM) and determine the dynamics of these modifications leading to an assumptive damaging mechanism of the protective coating. Mechanical, tribological and thermal shock tests of the thermal treated nanostructured coatings may bring additional data on the mechanisms of thermal degradation and avoid effectively the crack propagation and delamination along the interface $[35,36]$.

\section{Conclusions}

In this review, we show that DSC methods can be successfully applied both as a standard method for assessment of already existing technologies, in order to verify the reproducibility and durability of the nanostructured coating systems, but also as relatively simple and accessible methodology to study and predict the coating process parameters, based on well-established thermodynamic and kinetic models, allowing to preserve the nanostructures during thermal treatment of different novel multi-material coating systems, and study the complex correlations between material properties vs. synthesis and processing parameters in real environments.

The method may be used for optimization of all types of coatings, such as: polymers, hybrid organic-inorganic composites, metallics, inter-metallics and ceramics.
In the case of metallic coatings, DSC method could bring important knowledge on the activation energy of inter-metallic compounds formation during thermal treatment in different controlled atmospheres, thus leading to a better control of micro-structure and interlayers development during processing.

For inorganic and hybrid organic-inorganic coatings, DSC can be used to study the kinetic of thermal treatment process, leading to preservation of nanostructures with desired smart properties.

In the case of high temperature ceramic coatings, DSC can be used to establish the thermal treatment temperature, avoiding the degradation and / or delamination at the substrate-coatings interface.

This research was funded by Core Program, developed with the support of Romanian Ministry of Education and Research, contract no. 6N/2019, Acronym MULTIMET, projects no. 19190401 and 19190101.

Author Radu Robert Piticescu acknowledge the funding from H2020 ERAMIN II Programme, MONAMIX project ID 87, financed in the frame of grant 50/2018 UEFISCDI Romania.

Author Mihai Botan acknowledge the funding by the European Social Fund through the Sectoral Operational Programme Human Capital 2014-2020, through the Financial Agreement with the title "Scholarships for entrepreneurial education among doctoral students and postdoctoral researchers", Acronym "Be Entrepreneur! Contract no. 51680/09.07.2019 SMIS code: 124539 .

Author MD Romero-Sanchez would like to acknowledge the European Commission by the financial support of the MASTRO project, H2020 R\&I programme, contract no. 760940.3. 


\section{References}

1. Basic Research Needs for Materials under Extreme Environments. Report of the Basic Energy Science Workshop on Materials under Extreme Environments. Office of Basic Energy Sciences Department of Energy. 2008; http://www. sc.doe.gov/bes/reports/files/MUEE_rpt.pdf

2. P.M. Martin, Handbook of Deposition Technologies for Films and Coatings, 3rd ed. Elsevier, 2010

3. Materials Science Forum. 2010; doi:10.4028/www.scientific. net/MSF.631-632.73

4. M.E. Brown, P.K. Galagher, Handbook of Thermal Analysis and Calorimetry Recent Advances. Techniques and Applications, Vol. 5, Elsevier, 2008

5. G.W.H. Hohne, W.F. Hemminger, H.J. Flammersheim, Differential Scanning Calorimetry, 2nd Edition, Springer, 2003

6. M.E. Brown, Introduction to Thermal Analysis, 2nd ed. Kluwert Academic Publishers, 2001

7. C. Michaelsen, K. Barmak, T.P. Wiehs, Investigating the thermodynamics of thin film reactions by Direct Scanning Calorimetry, J. Phys. D Appl. Phys. 30 (1997) 3167-3186

8. T. Hatekeyama, F.X. Quinn, Thermal Analysis. Fundamentals and Applications to Polymer Science, 2nd ed., T, John Wiley \& Sons, 1999

9. F.J. Gotor, J.M. Criado, J. Malek, N. Koga, The universality of master plots for analyzing isothermal and nonisothermal experiments, J. Phys. Chem. A 104 (2000) 10777-10782

10. E. Chason, P.R. Guduru, Understanding residual stress in polycrystalline thin films through real-time and measurements and physical models, J. Appl. Phys. 119 (2016) 191101

11. M-S. Chu, S-K. Wu, Interreactions of TiAl3 Thin Film on Bulk $\gamma$-TiAl and on Bulk $\alpha 2-\mathrm{Ti} 3 \mathrm{Al}$ Alloys at $700-1000{ }^{\circ} \mathrm{C}$, Mater. Transac. 45 (2004) 1290-1298

12. C. Yang, Y. Hu, R. Shen, Y. Ye, S. Wang, T. Hua, Fabrication and performance characterization of $\mathrm{Al} / \mathrm{Ni}$ multilayer energetics films, Appl. Phys. A 114 (2013) 459

13. P.R. Halani, I. Kaya, Y.C. Shin, H.E. Karaca, Phase transformation characteristics and mechanical characterization of nitinol synthesis by laser direct deposition, Mater. Sci. Eng. A 559 (2013) 836-843

14. M. Mohri, M.N. Ahmadabali, Functionally graded shapememory and pseudoelastic response in Ni-Rich/Ti-rich and vice versa NiTi mulilayer thin films deposited on $\mathrm{Si}(111)$, JOM 67 (2015) 1585-1593

15. A. Ishida, Effects of grain size and co addition on the transformation temperatures of Ti-Ni-Zr thin films, Shape Mem. Superplasticity, 1 (2015) 408-417

16. R.DV. Espiritu, A.V. Amorsolo, DSC analysis of Cu-Zn-Sn shape memory alloy fabricated via electrodeposition route, J. Therm. Anal. Calorim. 107 (2012) 483-487

17. E.P. Georgiou, S. Dosta, J. Fernandez, P. Matteazzi, K. Kowalski, J. Kusinski, R.R. Piticescu, J.-P. Celis, Structural and tribological properties of nanostrcutured supersonic cold sprayed Ni-20 wt.\% Sn coatings, J. Therm. Spray Technol. 25 (2016) 1029-1039
18. R.W. Schwartz, M. Narayanan, Chemical Solution Deposition of Functional Oxide Thin Films, Thermodynamics and Heating Processes, Springer, 2013, 343-382

19. J. Ji, H. Sun, X-y. Mao, W. Wang, X. Chen, Structure and multiferroic properties of $\mathrm{Bi}_{5} \mathrm{FeTi}_{3} \mathrm{O}_{15}$ thin films prepared by the sol-gel method, J. Sol-Gel Sci. Technol. 61 (2012) $328-331$

20. K.D. Zhang, Z.R. Tian, J.B. Wang, B. Li, X.L. Zhong, D.Y. Guo, S.M. He, Preparation of $\mathrm{Cu}_{2} \mathrm{ZnSnS}_{4}$ thin films using spin-coating method with thermolysis and annealing, J. SolGel Sci. Technol. 73 (2014) 452-459

21. D. Alvarez, A. Collazo, C. Perez, Structural characterization and barrier properties of hybrid sol-gel films applied on tinplate, Surf. Coat. Technol. 321 (2017) 108-117

22. V.G. Plescan, V. Musat, A. Pimentel, T.R. Calmeiro, E. Carlos, L. Baroiu, R. Martins, E. Fortunato, Hybrid (Ag) $\mathrm{ZnO} / \mathrm{Cs} / \mathrm{PMMA}$ nanocomposite thin films, J. Alloys Compd. 803 (2019) 922-933

23. A. Zarkov, A. Stanulius, J. Sakaliuniene, S. Butkute, B. Abakeviciene, T. Salkus, S. Tautkus, A.F. Orliukas, S. Tamulevicius, A. Kareiva, On the synthesis of yttriastabilized zirconia: a comparative study, J. Sol-Gel Sci. Technol. 76 (2015) 309-319

24. C. Marinescu, A. Sofronia, C. Rusti, R. Piticescu, V. Badilita, E. Vasile, R. Baies, S. Tanasescu, J. Therm. Anal. Calorim. 103 (2011) 49-57

25. A.K. Pradhan, D. Hunrter, B.L. Hunter, J.B. Dadson, K. Zhang, R.R. Rakhimov, Oxide-based diluted ferromagnetic semiconductors: $\mathrm{ZnMnO}$ and $\mathrm{Co}: \mathrm{TiO}_{2}$, J. Appl. Phys. 99 (2006) 08M10

26. R.R. Piticescu, S.N. Valsan, M. Petriceanu, V. Badilita, I.A. Tudor, D. Taloi, B. Vasile, O. Raita, Kinetic studies on the hydrothermal crystallization of Co-doped nanostructured $\mathrm{TiO} 2$ anatase with ferromagnetic properties, J. Optoelectron. Adv. Mater. 17 (2015) 646-654

27. C. Gaidau, A. Petica, M. Ignat, L.M. Popescu, R.M. Piticescu, I.A. Tudor, R.R. Piticescu, Preparation of $\mathrm{SiO}_{2}$ doped $\mathrm{TiO}_{2}$ nanoparticles with thermal stability and photocatalytic properties and its application for leather surface functionalization, Arab. J. Chem. 10 (2016) 985-1000

28. S.B. Ulaeto, R. Rajan, J.K. Pancrecious, T.P.D. Rajan, B.C. Pai, Developments in smart anticorrosive coatings with multifunctional characteristics, Prog. Org. Coat. 111 (2017) 294-314

29. Z.-P. Zhang, X.-F. Song, L.-Y. Cui, Y.-H. Qi, Synthesis of polydimethylsiloxane-modified polyurethane and the structure and properties of its antifouling coatings, Coatings 8 (2018) 157

30. B.C. Roca, S.M.D. Romero, A.N. Arnaiz, P.I. Rodríguez, G.I. Martín, Synergetic effect of CNTs and graphite for electrical properties: joule effect. 5th World Congress on Materials Science and Engineering, 22-23rd August 2019, Valencia, Spain

31. E. Celia, T. Darmanin, E.T. De Givenchy, S. Amigoni, F. Guittard, Recent advances in designing super-hydrophobic surfaces, J. Colloid Interface Sci. 402 (2013) 1-18

32. A.M. Motoc, A.I. Tudor, M. Petriceanu, A. Celzard, R.R. PITICESCU, In-situ synthesis and attachment of colloidal $\mathrm{ZnO}$ nanoparticles inside porous carbon structures, Mater. Chem. Phys. 161 (2015) 219-227 
33. E.L. Corral, R.E. Loehman, Ultra-high temperature ceramic coatings for oxidation protection of Carbon-Carbon composites, J. Am. Ceram. Soc. 91 (2008) 1495-1502

34. D.R. Clarke, C.G. Levi, Materials design for the next generation thermal barrier coatings, Ann. Rev. Mater. Res. 33 (2003) 383-417
35. S. Ilina, G. Ionescu, V. Manoliu, R.R. Piticescu, Nanostructured zirconia layers as thermal barrier coatings, INCAS Bull. 3 (2011) 63-69

36. G. Ionescu, V. Manoliu, E. Alexandrescu, A. Stefan, A. Mihailescu, The behavior of multilayer ceramic protecting at thermal shock, INCAS Bull. 5 (2013) 25-32

Cite this article as: Anca Elena Slobozeanu, Simona Elena Bejan, Ioan Albert Tudor, Ana-Maria Mocioiu, Adrian Mihail Motoc, Maria Dolores Romero-Sanchez, Mihai Botan, Cristea George Catalin, Cursaru Laura Madalina, Radu Robert Piticescu, Cristian Predescu, A review on differential scanning calorimetry as a tool for thermal assessment of nanostructured coatings, Manufacturing Rev. 8, 1 (2021) 